\title{
LA TECNICA Y LA CRISIS FILOSOFICA DEL HUMANISMO
}

Sergio Sevilla*

\begin{abstract}
RESUMEN
Los acontecimientos civilizatorios que emblemáticamente representamos con nombres como Auschwitz o Hiroshima han hecho visible que la comprensión de la realidad como técnicamente abordable obliga a replantear problemas centrales para la filosofía: la omnipresencia de la técnica transforma el modo de vida de los individuos y las sociedades contemporáneas, el vínculo del hombre con la naturaleza y el vinculo social, no menos que los modos de construcción de la subjetividad humana. El presente escrito intenta oponer a la destrucción heideggeriana del sujeto la idea de que, en la presente crisis abierta por las posibilidades inéditas de las tecnologías, es imprescindible una reconstrucción del sujeto de la responsabilidad moral y política.
\end{abstract}

PALABRAS-CLAVE: Humanismo; Crisis; M. Heidegger.

\begin{abstract}
The civilizatory events that we emblematically represent under such names as Auschwitz or Hiroshima have made it clear that the understanding of reality as technically approachable compels us to reformulate some problems which are central to philosophy: the omnipresence of technique transforms the way of life of individuals and of contemporary societies, man's link with nature,
\end{abstract}

Catedrático de Filosofia y actualmente Director del Departamento de Filosofia - Universidad de Valencia. 
and social links, no less than the ways of constructing human subjectivity. In opposition to Heidegger's destruction of the subject, this paper tries to defend the idea that, in the present crisis opened up by the new possibilities of technology, it is imperative to reconstruct the subject of moral and political responsibility.

KEYWORDS: Humanism; crisis; M. Heidegger.

La polémica sobre el humanismo, como búsqueda de una solución moral a los retos de un mundo social en que la técnica ha producido los desastres que abreviamos con nombres emblemáticos como Auschwitz o Hiroshima, apa-reció, en un primer momento -1946-, como disputa particular en cuanto al modo de entender el existencialismo como filosofía. Pudo entonces entenderse como una delimitación de territorio entre los respectivos jefes de fila de un existencialismo, comprometido con los perdedores de la segunda guerra mun-dial, y otra forma de existencialismo nueva que se comprometía con la libertad. Esa percepción, parcialmente correcta, oculta, sin embargo, dos dimensiones constitutivas de la novedad de la situación histórica que la polé-mica expresa en conceptos: la omnipresencia de la técnica transforma el modo de vida de los individuos y las sociedades contemporáneas, el vínculo con la naturaleza y el vínculo social, no menos que los modos de construcción de la subjetividad humana, tanto al hacer la guerra como al vivir en paz, de un modo tan profundo y en una dirección tan desconcertante, que los saberes humanísticos no se ven tan sólo rezagados respecto al avance de la tecno-logía, en una hipotética carrera del progreso, sino que se encuentran cuestio-nados en el concepto mismo que los define: lo que hemos dejado de saber es qué es el hombre.

El tiempo histórico que inaugura y prefigura Auschwitz es, para Adorno, mucho más que un ejemplo de genocidio en la historia humana; es el tiempo en que la tecnología, posibilitada por la ciencia natural y por el control racional sobre las sociedades humanas, hace patente el poder del concepto como creador de

Educ. e Filos., Uberlândia, v. 21, n. 42, p. 229-250, jul./dez. 2007. 
vínculos de dominación, y de exclusión de todas aquellas formas de la experiencia no compatibles con la razón instrumental. El existencialismo y la teoría crítica se plantean como problema la posibilidad de habitar un mundo tecnificado. Nada es menos seguro que la vuelta al humanismo como solución, porque lo que está en cuestión es el funciona-miento y aún la comprensión de lo humano como sometido a la lógica de las cosas. La cosifi-cación de lo humano al ser configurado por la lógica de las mercancías, o al entenderse a sí mismo como un ente objetivo entre los entes en la tradición filosófica y científico-técnica occidental, cuestiona el propio recurso a lo humano y sus valores puesto que han entrado en crisis justa-mente las cate-gorías adecuadas para entenderlo. No es que no sea necesario un nuevo humanismo, es que hemos dejado de saber qué es el hombre, que parece haber entrado en un proceso histórico nuevo de transfiguración que deja inservibles las antropologías conocidas como sustrato hipotético para una reconstrucción; los métodos de reconstruir la idea de hombre sobre algún esquema conocido excluyen justamente la posibilidad de entender lo que hay de irreversiblemente nuevo en la forma contemporánea de vida, cuyo centro de gravedad y cuya dirección de movimiento son justamente irreductibles a las teorías previas y a los valores del pasado. La posibilidad de expresar conceptualmente el sentido y las implicaciones de ese cambio es lo que separa, de un modo no reductible, las posiciones teóricas de Heidegger, Sartre o Adorno y lo que mueve el pensamiento vivo desde esa mitad del siglo XX: sabemos que el proceso autoconstituyente del hombre y de la sociedad ha sido alterado por la extensión de la técnica, pero está por pensar qué es exactamente la técnica y en qué sentido se está transformando el ser humano y la sociedad.

El proceso que, a la vez, narro e interpreto, puesto que no hay narración sin valoración, es el mismo proceso de crisis, a la vez del humanismo y de las humanidades, al que nos estamos confrontando en el momento presente. La afirmación de que el proceso es el mismo no debe entenderse en su literalidad: no intento sugerir que el proceso sea idéntico a sí mismo con toda 
independencia de las conceptualizaciones y valoraciones de quienes somos parte de él; lo que con la acotación "mismo proceso" quiero decir es que, desde el salto cualitativo que representan Auschwitz, Hiroshima o el desarrollo de la biotecnología, el crecimiento de la potencialidad tecnológica ha ido confirmando el fenómeno de ruptura con la concepción que el hombre tenía de sí mismo. Intentaré describir lo que, a mi juicio, constituye a los fenómenos de esa ruptura.

He mencionado "Auschwitz" como fenómeno porque ha sido caracterizado filosóficamente con profundidad como punto de ruptura por Adorno; he mencionado también "Hiroshima" porque el surgimiento de la era atómica, como posibilidad de "suicidio" de la humanidad, pone en cuestión el optimismo ilustrado sobre el progreso de una especie que no puede, casi por razones conceptuales, pensarse como capaz de consumar el acto terrorista de aniquilarse a sí misma. Y he mencionado la biotecnología porque no quiero que nadie entienda la crítica de la técnica como un ejercicio de condena romántica que añora una supuesta relación armoniosa del hombre con el mundo y consigo mismo, o como una condena moral reaccionaria de la técnica, que no sabemos en nombre de qué tipo de sujeto moral habría de intentar legitimarse.

No creo necesario enfatizar que el desarrollo de la técnica, y la extención social de su uso, ha introducido cambios tales en nuestra forma de vida que ésta se ha hecho impossible de imaginar sin ellos; pero tampoco debe ser ignorado, ni pasado por alto; se ha hecho simplemente absurdo pensar un mundo habitable por nosotros sin un uso masivo de energías de todo tipo, de antibióticos, o hasta de la ya vislumbrable medicina genética, o de las telecomunicaciones. Los problemas que la presencia de la técnica plantea no se entienden desde una elemental axiología de la aceptación o del rechazo. La técnica ha cambiado no sólo los valores sino los hechos, por apelar a una terminología que se va haciendo obsoleta. Las posibilidades que la técnica actual pone en nuestras manos no sólo crean situaciones inmanejables para los valores del humanismo clásico sino, sobre todo, como ya he apuntado, para su sujeto; ello sucede porque el sujeto de la acción se define por los 
límites de sus posibilidades; y la técnica ha desplazado esos límites, y la propia noción de lo que es acción posible.

Un cuestionamiento profundo del modo en que esa apertura de posibilidades altera radicalmente la forma humana de instalación en la realidad puede beneficiarse del análisis que hizo Heidegger en su célebre conferencia sobre la técnica. Volver a considerar los términos en que se registra filosóficamente la ruptura con el sujeto clásico, en los escritos de 1946 y 1952, significa por mi parte señalar el momento en que se toma conciencia de una disociación entre la imagen clásica del hombre que el humanismo ilustrado ha transmitido, y la experiencia histórica efectiva, tras la segunda guerra mundial, de que esa imagen no nos permite entendernos a nosotros mismos; es un fenómeno de ruptura de sentido, de continuidad, que inaugura un tiempo nuevo en el que todavía nos encontramos: la acción, individual y colectiva, ha de hacer una elección entre posibilidades técnicas nuevas; y para esa elección no nos prepara el humanismo transmitido.

Ahí se inscribe la necesidad de prolongar el diálogo que abrieron las intervenciones de Sartre y Heidegger sobre el humanismo, y las reflexiones de Adorno sobre la vida dañada. Lo que Heidegger propone es una nueva actitud ante el ser, que nos permita captar otros sentidos, "otros" que el sentido de dominio sobre la naturaleza, los otros hombres y el propio ser humano que constituyen el núcleo de la tecnociencia, que es nuestro destino actual. Para ello, es preciso intentar una posición exterior a esa de dominio, lo que implica una concepción de lo humano distinta a la que se deriva de la posición sujeto-objeto, y una comprensión del pensar más originaria del ser-ahí, que elabora otras dimensiones de la experiencia y, sobre todo, de la verdad y la libertad, del saber teórico y de la práctica. Voy a intentar adoptar su concepción, como punto de vista hipotético, guiado por dos preguntas: 1.-¿Cuál es la posición que, siquiera sea hipotéticamente, hemos de poner entre paréntesis? 2.-¿Cómo se caracteriza la nueva posición en términos de "pensar", "verdad" y "libertad"?.

Heidegger caracteriza la posición del sentido extraído en actitud de dominio como "interpretación técnica del pensamiento". 
En el pensamiento que indaga causas, se entiende "el actuar como la producción de un efecto" 1 , en vez de entenderlo como un "llevar a cabo", donde "llevar a cabo significa desplegar algo en la plenitud de su esencia, guiar hacia ella, producere" ${ }^{2}$. Esta segunda concepción del "producere", que como veremos lleva a otra concepción de la técnica próxima al arte, y a una comprensión del pensar lejana al esquema sujeto-objeto y a la indagación de causas, sitúa el problema del destino técnico de la humanidad ante este designio: "nos tenemos que liberar de la interpretación técnica del pensar" ${ }^{\prime \prime}$. Ese es el verdadero peligro para Heidegger, y no los efectos perversos, esperados o inesperados, de tal o cual modo de utilización de la técnica que tendemos a abordar en términos de una "definición instrumental y antropológica de la técnica". Esta concepción está inscrita dentro de la interpretación técnica del pensar y, por tanto, no puede llevarnos a una posición distinta. Este es precisamente el tipo de estrategia intelectual inscrita en el humanismo moderno que ha muerto: "La definición únicamente instrumental, únicamente antropológica de la técnica se convierte en principio en algo caduco; no se deja completar con la simple adición de una explicación metafísica o religiosa" ${ }^{4}$. No se trata de establecer un control de la técnica basado en los valores, p.e., de los derechos del "hombre" porque la concepción misma del hombre como sujeto está inscrita en la lógica de la "interpretación técnica del pensar", con lo cual reproduce aquel engranaje (Gestell) al que sólo en la intención se opone. No es sólo la correlación sujeto-objeto lo que ha de ponerse entre paréntesis, sino también, consecuentemente, la noción clásica de teoría en su articulación con la práctica.

“Lo peligroso no es la técnica. No hay nada demoníaco en la técnica, lo que hay es el misterio de su esencia. La esencia de la

1 M.Heidegger, Carta sobre el humanismo, Madrid, Alianza, 2001, trad. cast. de H. Cortés y A. Leyte, p.11.

2 M. Heidegger Carta ..., ya citada, loc. cit.

3 M. Heidegger Carta ..., ya citada, p.13.

${ }^{4}$ M. Heidegger Carta ..., ya citada, p.23.

Educ. e Filos., Uberlândia, v. 21, n. 42, p. 229-250, jul./dez. 2007. 
técnica como un sino de hacer salir lo oculto, es el peligro". ${ }^{5}$

Heidegger sitúa la noción de "verdad" en un nivel previo al del sujeto que realiza enunciados lógicos de los que se puede predicar verdad o falsedad en la interpretación teórica del pensar. Según él, hay un fenómeno previo de verdad: el desocultamiento del ser al existente. Desde esa posición de la verdad como desocultamiento, la verdad proposicional vinculada a la lógica es un modo particular de desocultamiento que ya encierra una posición ontológica de dominio que prefigura la técnica. En esta posición, el hombre como sujeto emplaza al ser en posición de objeto para producir una teoría que rige la acción como efecto suyo y, de este modo, se justifica como útil. La propia posición teórica es un útil, y su producto está destinado a la utilidad como único criterio de validez del producto teórico. Ese es el peligro que encierra el hecho de que nos limitemos al modo técnico de pensar.

Frente a esa caracterización de la "esencia de la técnica", Heidegger propone un cambio en la comprensión del pensar y el obrar - un cambio en la comprensión de la relación entre theoría y praxis - que nos sitúe en la posibilidad de una comprensión del ser distinta al dominio; en la Carta sobre el humanismo afirma: "El pensar no se convierte en acción porque salga de él un efecto o porque pueda ser utilizado. El pensar sólo actúa en la medida en que piensa. Este actuar es, seguramente, el más simple, pero tambien el más elevado, porque atañe a la relación del ser con el hombre. Pero todo obrar reside en el ser y se orienta a lo ente. Por el contrario, el pensar se deja reclamar por el ser para decir la verdad del ser" 6

Desde el punto de vista así logrado, entro a considerar la segunda pregunta: ¿Cómo se caracteriza la "nueva" posición en términos de "pensar", "verdad" y "libertad"? La respuesta a esta pregunta sólo puede entenderse como un sumario intento de pensar una posición del hombre respecto al ser distinta de la de dominio,

5 M.Heidegger, Conferencias y artículos, Barcelona, Ediciones del serbal, 1994, trad. cast. De E. Barjau, p.29.

6 M.Heidegger, Carta..., ya citada, p.12. 
tras haber identificado a éste con la posición del pensar lógico. Ocupa, por tanto, un lugar paradójico, en los márgenes de la lógica, lo que lo convierte en un pensar virtualmente potente en la crítica, pero sumamente precario en la caracterización y defensa de su posición propia. Ocupa el espacio de esas nociones límite, como "transvaloración de todos los valores" en Nietzsche, que permiten ver como en un chispazo, con una claridad de otro modo imposible, los límites de los valores cuestionados, y aún los efectos perversos de los procesos históricos de realización de la racionalidad, pero que, por eso mismo, no pueden defenderse como territorio conquistado por la razón, y su justificación propia es sumamente precaria. De ellos, como de la cosa en sí kantiana, sólo puede hablarse negativamente, esto es, para poner límites a la pretensión de totalidad que lo dado, por el hecho de ser dado, siempre acaba por postular.

"Verdad" como aletheia, y "libertad" aparecen juntas en ese nivel previo a la subjetividad consciente en que los sitúa Heidegger. "Siempre prevalece, de parte a parte, en el hombre el sino de hacer salir lo oculto. Pero no es nunca la fatalidad de una coacción. Porque el hombre llega a ser libre justamente en la medida en que pertenece a la región del sino, y de ese modo se convierte en uno que escucha, pero no en un oyente sumiso y obediente"

Se intenta caracterizar al hombre, a la verdad y a la libertad en un momento de su relación con el ser - el de su experienciaprevio al de la adquisición de su posición de sujeto de la conciencia cognoscente y moral. Leído en términos hegelianos de historia de la conciencia cabría situarlo en un momento en que hay experiencia sensible y un cierto grado de sentimiento de sí, pero no se ha logrado todavía el nivel de la conciencia de sí que será punto de partida de la descripción fenomenológica de la razón. Por eso, "verdad" no es todavía verdad proposicional, ni "libertad" "está originariamente ordenada... a la voluntad, ni tan siquiera a la causalidad del querer humano"8. "Causalidad", como categoría del sujeto y de la explicación teórica, parece ser un indicio de que

7 M.Heidegger, Conferencias ..., ya citado, pp.26-27

8 M.Heidegger, Conferencias..., ya citado, p.27.

Educ. e Filos., Uberlândia, v. 21, n. 42, p. 229-250, jul./dez. 2007. 
estamos en el interior del pensar técnico, y debe ser rehuida para descender a un nivel más originario. ¿Qué significa, entonces, "libertad" si no es ni arbitrio ni autonomía? ("la libertad de lo libre no consiste ni en la desvinculación propia de la arbitrariedad ni en la vinculación debida a meras leyes" ${ }^{\prime 9}$ ). Para el análisis de Heidegger, "la libertad es lo que oculta despejando, y en su despejamiento ondea aquel velo que vela lo esenciante de toda verdad y hace aparecer el velo como lo que vela. La libertad es la región del sino, que pone siempre en camino un desocultamiento"10. "Libertad" caracteriza la posición en que el hombre "escucha" el ser - se mantiene abierto a su experiencia "haciendo aparecer el velo como lo que vela" - y adopta, por tanto, una actitud receptiva a otro sentido de esa experiencia distinto del que impone la actitud de dominio que emplaza el sentido de la experiencia en términos que prefiguran y posibilitan la técnica. Esa actitud de apertura en la escucha de otro posible sentido del ser ha de ser contraria a "la furia del solicitar que desfigura toda mirada dirigida al acaecimiento propio del desocultamiento, y de este modo, pone en peligro desde su fundamento el respecto a la esencia de la verdad"11. Esa actitud ha de ser un modo de hacer salir de lo oculto "más inicial (y que) será capaz tal vez de llevar a lo que salva a su primer lucir"12. Esa región "más inicial" acercaría de nuevo la pertenencia a la poiesis del arte y la técnica, y se ubica en un modo del pensar en que el preguntar no se dirige al dominio, porque en ella "el preguntar es la piedad del pensar"13.

La reconducción de la esencia de la técnica a un modo de verdad en que vuelve a encontrarse con la verdad del arte, la prioridad concedida a una apertura de la experiencia, en posición de cuidado piadoso hacia el sentido recibido, contrasta de forma tan poderosa con la destructividad de nuestra relación técnica con

9 M.Heidegger, Conferencias ..., ya citado, p.27.

${ }^{10}$ M.Heidegger, Conferencias..., ya citado, p.27.

${ }^{11}$ M.Heidegger, Conferencias..., ya citado, pp.34-35.

${ }^{12}$ M.Heidegger, Conferencias..., ya citado, p.36.

${ }^{13}$ M.Heidegger, Conferencias..., ya citado, p.37. 
la naturaleza, con el mundo social y con nosotros mismos inscrita en el mundo presente, que, a pesar de su precariedad ya subrayada, ha tenido una enorme capacidad de influencia sobre la necesidad de pensar de un modo distinto la articulación entre saber, técnica y valores humanísticos. Desde la voluntad de pensar de nuevo esa articulación es necesario medir el alcance de su propuesta, sólo en apariencia modesta.

Afrontemos directamente el principal interpelado en la crisis de los valores humanistas, en parte provocada por las nuevas posibilidades tecnológicas. Esa noción interpelada, si no cuestionada en su significado habitual, resulta ser la idea de responsabilidad, núcleo de nuestra identidad como sujetos previo incluso a la noción de imputabilidad axiológica y moral. La noción de responsabilidad marca la frontera entre el existente y el sujeto; el sentido de la operación de Heidegger es un descenso a estratos más originarios puesto que, según su diagnóstico, habríamos fracasado al fijar al sujeto como posibilidad única: "El descenso, sobre todo cuando el hombre se ha estrellado ascendiendo hacia la subjetividad, es más dificil y peligroso que el ascenso", nos dice en la Carta sobre el humanismo ${ }^{14}$. Puede que sea así, y que el movimiento de descenso, como búsqueda de nuevo sentido del ser, o como indagación en el inconsciente, sea necesario; pero, si lo es, sólo puede justificarse tal necesidad como momento de una nueva ascensión a una subjetividad que pueda responder, en el pensar y en el hacer, de sus posibilidades de intervención en el mundo presente.

¿Qué podemos aprender en "el descenso" respecto al tema clave de la responsabilidad? Ante todo ha de aclararse que si puede hablarse de "responsabilidad" en un nivel en que el descenso a lo originario nos abre un espacio que queda por debajo del constructo que es el sujeto, por debajo, por tanto, de la oposición "theoría/ praxis", ello implica que "ser responsable", en este espacio, no tiene - o no tiene todavía - un sentido moral. Como aclara Heidegger

\footnotetext{
${ }^{14}$ M.Heidegger, Carta, ya citada, p.72.
} 
en Carta sobre el humanismo "este pensar no es ni teórico ni práctico. Acontece antes de esta distinción"15; y en ejercicio de ese pensar, en La pregunta sobre la técnica asegura: "Los hombres de hoy nos inclinamos con excesiva facilidad a entender el ser responsable, o bien en sentido moral, como un estar en falta, o bien si no como un modo del efectuar. En ambos casos nos cerramos el camino hacia el sentido inicial de eso que más tarde se denominó causalidad. Mientras no se abra este camino tampoco avistaremos lo que es propiamente lo instrumental que descansa en lo causal"16.

La noción de responsabilidad es traída a colación en el intento de desmontar la idea de instrumentalidad que suyace a la comprensión de la técnica como instrumento al servicio de un fin; para esa deconstrucción Heidegger analiza la noción de causa, en la teoría aristotélica de las cuatro causas, y equipara el término griego aitía a "ser responsable": "las cuatro causas son los cuatro modos - modos que se pretenecen unos a otros - del ser responsable"17. Yendo más lejos, establece su equivalencia con el "ser deudor" por parte de lo efectuado; si decimos de la plata que es causa material de una copa de plata estamos diciendo que "es corresponsable de la copa"; y decimos tambien que "ésta es deudora de la plata, es decir, tiene que agradecerle a la plata aquello de lo que está hecha"18. Lo mismo puede decirse de las otras tres causas y así, "Los cuatro modos de ser responsable llevan a algo a aparecer (...). El ser responsable tiene el rasgo fundamental de dejar venir el advenimiento. En el sentido de este dejar venir, el ser responsable es el ocasionar"19. De ahí, a través de la proposición 205b del Symposion de Platon, se establece la conexión entre "responsabilidad", "presencia" y "producción". Platon dice: "Toda acción de ocasionar aquello que, desde lo no presente, pasa y avanza a presencia es poiesis, producir, traer-ahí-delante". En el

${ }^{15}$ M.Heidegger, Carta, ya citada, p.80.

${ }^{16}$ M.Heidegger, Conferencias..., ya citado, p.13.

${ }^{17}$ M.Heidegger, Conferencias, ya citado, p.12.

${ }^{18}$ M.Heidegger, Conferencias, ya citado, p.12.

${ }^{19}$ M.Heidegger, Conferencias, ya citado, p.14. 
análisis de Heidegger ello no implica la oposición conceptual fisis/ poiesis porque "tambien la fisis, el emerger desde sí, es un traer ahí delante, es poiesis" ${ }^{20}$. Lo que importa a Heidegger es que los cuatro modos del ser responsable lo son del producir en el sentido de traer a presencia lo oculto, como la fisis, son responsables de la verdad en el sentido de aletheia.

De este análisis por descenso a lo originario extrae Heidegger dos pensamientos que conciernen a nuestro tema. Primero, el pensamiento de que "La técnica no es un mero medio, la técnica es un modo del salir de lo oculto. Si prestamos atención a esto se nos abrirá una región totalmente distinta para la esencia de la técnica. Es la región del desocultamiento, es decir, de la verdad". Y, en segundo lugar, una conexión culturalmente sorprendente: "La techné pertenece al traer-ahí-delante, a la poiesis; es algo poiético" 21

La técnica es un modo del salir de lo oculto cuya peculiaridad esencial hemos de captar para poder abrirnos a otros modos del desvelamiento, esto es, de la verdad. El modo de verdad que domina en la técnica moderna no es el de la poiesis; "El hacer salir de lo oculto que prevalece en la técnica moderna es una provocación que pone ante la naturaleza la exigencia de suministrar energía que como tal puede ser extraída y almacenada" ${ }^{22}$. La ruptura de la técnica moderna con lo que las sociedades tradicionales usaron como technai consiste en esa provocación que emplaza a los elementos naturales a dar de sí energía almacenable: “Al aire se lo emplaza a que dé nitrógeno, al suelo a que dé minerales, al mineral a que dé, por ejemplo, uranio, a éste a que dé energía atómica, que puede ser desatada para la destrucción o para la utilización pacífica" ${ }^{23}$. El problema originario no es, para este análisis, el uso que de la técnica se haga (de la energía atómica, en su ejemplo) para la destrucción o la paz; en un nivel más originario, pre-moral si cabe decirlo así, el problema reside en un modo de acceder a la

${ }^{20}$ M.Heidegger, Conferencias, ya citado, p.14.

${ }^{21}$ M.Heidegger, Conferencias, ya citado, p.15.

${ }^{22}$ M.Heidegger, Conferencias, ya citado, p.17.

${ }^{23}$ M.Heidegger, Conferencias, ya citado, p.17.

Educ. e Filos., Uberlândia, v. 21, n. 42, p. 229-250, jul./dez. 2007. 
verdad que promueve "la máxima utilización con el mínimo gasto" $^{24}$. Si la técnica desoculta emplazando en el sentido de la provocación, "el hacer salir lo oculto desoculta para sí mismo sus propias rutas (...) y las desoculta dirigiéndolas" ${ }^{\prime 25}$. Lo sacado a la luz lo es como "reserva", como "existencias". Al ocultar las propias rutas de desocultamiento, el hombre pierde su función como lugar de la verdad. Pero ello no hace de la esencia de la técnica un problema moral ni antropológico. Heidegger se pregunta: “¿acontece este salir de lo oculto en algún lugar que estuviera más allá de todo hacer humano? No. Pero tampoco acontece sólo en el hombre ni de un modo decisivo por él" ${ }^{26}$.

Reconocemos en esta respuesta el motivo central heideggeriano contra el humanismo de Sartre y, en general, contra todo humanismo, mezcla de biologismo y ética, encuadrados ambos en la comprensión metafísica del ser como ente, que ha hecho posible la técnica y oculta su esencia. No es de ese tipo de polémica del que podemos esperar hoy extraer esclarecimientos para nuestro tema. La cuestión es, más bien, averiguar qué perspectivas se nos abren de aceptar la posición límite que permite su diagnóstico a Heidegger, a saber, su afirmación: "Y el apoyo para toda conducta lo regala la verdad del ser" 27 . No es sencillo presentar con claridad el núcleo de su posición; pero si yo la entiendo bien, puede esquematizarse así: el modo de desocultamiento que es la técnica puede ocultar otros sentidos del ser: "el estado de desocultamiento según el cual la naturaleza se presenta como una trama efectiva y computable de fuerzas puede, ciertamente, permitir constataciones correctas, pero, precisamente debido a estos resultados, es posible que permanezca el peligro de que la verdad se retire en todas direcciones" ${ }^{28}$. Es evidente que si la técnica no es un peligro porque las proposiciones científicas en que se apoya sean falsas, ni por

${ }^{24}$ M.Heidegger, Conferencias, ya citado, p.18.

${ }^{25}$ M.Heidegger, Conferencias, ya citado, p.19.

${ }^{26}$ M.Heidegger, Conferencias, ya citado, p.25.

${ }^{27}$ M.Heidegger, Carta..., ya citada, p.86.

${ }^{28}$ M.Heidegger, Conferencias, ya citado, p.28. 
prematuras y poco originarias razones éticas, debemos precisar en qué sentido se afirma el peligro de que "la verdad se retire en todas direcciones".

La respuesta sumaria es que, en el mundo de la técnica, que en teoría realiza el sueño humanista de que el hombre sea señor de la naturaleza, "la verdad es que hoy el hombre no se encuentra en ninguna parte consigo mismo, es decir, con su esencia. El hombre está de un modo tan decidido en el séquito de la provocación de la estructura de emplazamiento, que no percibe ésta como una interpelación, que deja de verse a sí mismo como el interpelado, y con ello deja de oir todos los modos como él ec-siste desde su esencia en la región de una exhortación, y con ello nunca puede encontrarse consigo mismo" 29

La descripción del hombre como interlocutor del ser, que tiene su casa en el lenguaje, la insistencia en el oído sobre la vista, es el principal punto de Heidegger para atacar lo que le parece la esencia de la desviación de la mentalidad técnica: la idea de hombre autónomo. La conversión del cuidado en piedad de lo otorgado, o acogimiento del sentido del ser que permitiría traer a desocultamiento, al modo de la poiesis, es decir, de un modo distinto al del dominio que encarna la técnica, apunta a la destrucción del sujeto moderno que, en su diagnóstico, constituye un avatar histórico ya agotado. La cuestión del humanismo es la cuestión del sujeto; es ella la que lo enfrenta a un Sartre que reivindica el cogito, como ya hiciera Husserl en 1929, contra la deconstrucción del sujeto cartesiano que realiza Heidegger en Ser y tiempo. ¿Qué significado tiene para nosotros ese debate? Es dificil responder directamente a esta cuestión pero, en todo caso, una cosa es clara: no tiene el mismo sentido que tuvo para Husserl, que lo convirtió en base de la defensa de los valores racionales de una civilización cuyo núcleo siente atacado por su discípulo; ni siquiera el mismo que para Sartre, que quiere hacer del sujeto condenado a ser libre un nuevo punto de partida para la sociedad de 1946.

${ }^{29}$ M.Heidegger, Conferencias, ya citado, p.29.

Educ. e Filos., Uberlândia, v. 21, n. 42, p. 229-250, jul./dez. 2007. 
Sin desdeñar en absoluto los valores que en esos debates están en juego, ni las diferencias de posición entre los interlocutores, que no nos merecen el mismo aprecio, es importante señalar los motivos por los que la posición de Heidegger sigue interpelándonos.

En primer lugar, y aunque nuestra interpretación del hecho pueda ser bien distinta, hemos de compartir la percepción de que el modo moderno de pensar el sujeto se ha agotado. El optimismo de Husserl para el que un sujeto trascendental puede fundar una ciencia rigurosa de esencias, entre las cuales están las esencias objetivas de valor en que se funda nuestra civilización, no parece poder sobrevivir a los desafíos de un tiempo posterior a Auschwitz. En ese sentido, al menos, la idea de un sujeto racional autónomo como base de una civilización sostenible no resulta plausible después de 1945. Pero, como subraya Sartre, no parece que podamos contar con otra cosa que con el hombre responsable en un tiempo en que la idea de Dios ha muerto, y tampoco podemos creer en una filosofía de la historia como progreso objetivo.

En segundo lugar, la invitación a "el descenso, sobre todo cuando el hombre se ha estrellado ascendiendo a la subjetividad" no tiene por qué ser un camino sin valor, sobre todo porque la indagación originaria no está obligada a prohibir el ascenso a un sujeto nuevo, reconstruido sobre bases más firmes, arraigadas en lo que de nuevo hay en nuestra situación histórica. No es una mera ocurrencia puesto que la idea central de responsabilidad exige necesariamente que alguien responda y se haga cargo de la nueva situación creada por la técnica ${ }^{30}$. Veamos el para qué del descenso, y el por qué de la necesidad de un nuevo camino ascendente.

${ }^{30}$ Es cierto que Heidegger, en $\boldsymbol{E l}$ ser y el tiempo, inscribe la responsabilidad en el ser-ahí ( : “En el estado de ánimo es siempre ya 'abierto' afectivamente el 'serahí' como aquel ente a cuya responsabilidad se entregó al 'ser-ahí' en su ser como el ser que el 'ser-ahí' ha de ser existiendo", obra mencionada, México, F.C.E., 1967, p.152); pero es problemático que la responsabilidad del ser-ahí exceda la de hacerse cargo de las posibilidades existencialmente propias; y hace falta más que eso para construir un concepto de responsabilidad moral y político que pueda hacerse cargo de las nuevas posibilidades civilizatorias que estamos señalando en el texto. 
El descenso hacia lo originario que Heidegger lleva a cabo tiene, sobre todo, la virtualidad de señalar que la tecnología no es un mero hecho, ni un mero conjunto de instrumentos al servicio de un modo de vida que tiene valores y fines propios a los que sirve; sino que, más bien, encierra una auto-comprensión del hombre, en la medida en que entiende de un modo y no de otro su vínculo con la naturaleza, el vínculo social y el vínculo intrasubjetivo. La comprensión conjunta de esos vínculos - que Heidegger resume bajo la enigmática expresión "sentido del ser" - configura un lenguaje que imprime su carácter a nuestra forma de vida que, así, no puede considerarse como una fuente independiente de valores últimos, respecto de los cuales la técnica sería instrumento. Tal concepción supone al hombre como esencia, en vez de aceptarlo como un ser que se hace a sí mismo al establecer determinados vínculos con los demás, consigo mismo y con la naturaleza. El sujeto como esencia, o como conciencia eidética, se ha estrellado; pero el proceso de la acción sigue abierto y sus posibilidades son nuevas; el hombre tiene que seguir actuando en la creación de vínculos de sentido con la sociedad y con la naturaleza. Lo que la meditación heideggeriana señala, en ese nivel originario que sitúa por debajo de la idea de sujeto, es una actitud de atención y receptividad para con todo lo que es que devuelva a su lugar propio a la exigencia de entender para dominar; de este modo el hombre puede resituar su comprensión de sentido en esa atenta escucha receptiva, que es lo contrario de su exigencia agresiva. Decir que lo que escucha es lo que el ser envía no es sino una forma de poner un límite a la autonomía como agresión, sin definir, ni poder esperar definir la naturaleza de ese límite. Lo que cuenta es que el ser autónomo se sepa limitado, y lo sienta con "verdad", aún cuando la naturaleza pre-teórica de esa verdad tampoco nos permita pedir demostraciones. La caracterización de un producir poético, en que la técnica se ubique en posición no hostil con el arte, señala una dirección en la que no es inútil profundizar.

¿Por qué plantear entonces la necesidad de un nuevo ascenso hacia el sujeto? Porque el salto cualitativo en las posibilidades de existencia que abre la técnica plantea exigencias que sólo puede

Educ. e Filos., Uberlândia, v. 21, n. 42, p. 229-250, jul./dez. 2007. 
atender un sujeto de responsabilidad.

La ruptura en la imagen del hombre que encontramos tanto en la sartreana "condena a ser libre" como en la afirmación de Heidegger de que "el hombre se ha estrellado ascendiendo a la subjetividad", dejando de lado por el momento las profundas diferencias de posición conceptual y valorativa que implican, es una ruptura sintomática del inicio de un cambio de época. No sólo la técnica ha desbordado $-\mathrm{y}$, a veces, ha desmentido trágicamente - las expectativas emancipatorias para el hombre que en ella depositó la construcción ilustrada del sujeto moderno; los cambios cualitativos introducidos por la técnica han colocado su único sujeto posible de responsabilidad, el hombre desde mediados del siglo XX, ante una profunda alteración de su propia identidad. No se trata, tan sólo, de que, después de Auschwitz, cualquier extracción de sentido que el pensamiento construya a partir de esa experiencia histórica resulte sospechosa de falsear y encubrir la magnitud de la destrucción y el sufrimiento de las victimas. Se trata también de que el desarrollo de la técnica pone al hombre en situación de responsable de decisiones que, hasta ahora, estaban inscritas en la lógica de lo que sólo podían hacer la naturaleza, Dios o el destino. Por primera vez, la técnica hace posible que "alguien" decida la eliminación atómica de toda vida sobre la tierra; se convierte así en posibilidad histórica lo que Kant había llamado "estilo terrorista de imaginarse la historia humana", y que el crítico ilustrado de la razón había desechado de este modo sumario: "la caida a peor no puede continuar sin cesar en la historia humana, porque al llegar a cierto punto acabaría destruyendose a sí misma" ${ }^{31}$. Esta posibilidad le resulta simplemente imposible de pensar desde la perspectiva de quien ha equiparado los intereses últimos de la razón con el "interés de la humanidad que no está subordinado a ningún otro interés superior" ${ }^{\prime \prime 2}$. Se puede ver en las

${ }^{31}$ E.Kant, Filosofía de la historia, México, F.C.E., 1979, trad. cast. E. Ímaz, p.99.

${ }^{32}$ E.Kant, Crítica de la razón pura, Madrid, Alfaguara, 1978, trad. cast. P. Ribas, A798-B826, p.626. 
nuevas posibilidades técnicas que obligan a enfrentarse a ese límite de la razón, que no puede pensar la autodestrucción de la especie, el final del humanismo moderno, de la racionalidad que sólo concibe el mundo como ente en posición de objeto, el final del ideal de autonomía basado en esa concepción de la racionalidad; por eso ha hecho fortuna esa expresión de Heidegger según la cual "sólo un dios puede todavía salvarnos". Sartre lo interpreta como la muerte de la ilusión del hombre como esencia vinculada a valores apriorísticos que ha de aceptarse con autenticidad existencial, asumiendo una responsabilidad ilimitada por la creación de sí mismo y de los demás; si no hay un dios, sólo el hombre puede responder de lo que pase con la técnica; sólo la veracidad con que decidimos entre cursos alternativos de acción, y el hecho de asumir la responsabilidad de esa decisión, puede orientarnos en un mundo de posibilidades abiertas.

A primera vista parece una alternativa de hecho trágica, pero conceptualmente clara: desplazamos la responsabilidad a lo que el ser nos depare, o la asumimos como cuestión propia. No trato de separar tajantemente "lo que acaece", de un sujeto "a quien acaece", construyendo lo que sería una falsa alternativa. En todo caso, aquello de lo que se ha de responder es una posibilidad nueva en la historia de la especie humana. Pero si las posibilidades nuevas lo son de algo tan crucial ¿no habrá de ser también nuevo el sujeto que las ejerza y deba hacerse cargo de las consecuencias de su ejercicio? La responsabilidad es ineludible porque es seguro que "alguien" va a elegir el uso de las posibilidades nuevas, puesto que se trenzan con deseos y necesidades de nuestra vida cotidiana. Estamos de hecho eligiendo, y lo haremos cada vez en mayor medida, entre posibilidades inauditas, en sentido literal: nunca antes oídas; dejemos de lado el patetismo de un acto único de eliminación de la vida, y pensemos en la posibilidad de hacer inhabitable el planeta a las generaciones futuras, por la ruptura del biosistema que puede derivarse del uso de objetos tan cotidianos como el refrigerador o el automóvil, de los que, a la vez, no podemos imaginarnos prescindir. $\mathrm{O}$ bien, pensemos en las decisiones que ya se están tomando sobre la base de las posibilidades técnicas de la

Educ. e Filos., Uberlândia, v. 21, n. 42, p. 229-250, jul./dez. 2007. 
ingeniería genética; ¿es lícito decidir tener un hijo para utilizarlo como donante de médula ósea con el fin de salvar la vida a un hermano con leucemia? Hay que tomar una decisión inaudita, pero cualquiera puede verse en esa situación; $\mathrm{y}$, lo que es más, algunos ya se han visto en ella y ya han decidido. O bien, ¿será lícito que el individuo pueda construir colecciones de sí mismo para mantenerse con buena salud, consumiéndose a sí mismo, como consume otros objetos, en una especie de "canibalismo genético"?; o bien, ¿es moralmente aceptable la "meritocracia hereditaria", como ya se la llama, por selección de los rasgos genéticos favorables de los padres? Estas preguntas, que no son producto de mi imaginación, aparecen en un libro de F. Fernández Buey titulado Ética y filosofía política, que, según la solapa, "está dirigido por igual a los estudiantes de humanidades (...) y a los aspirantes científicos" $\mathrm{y}$, según una nota, toma la expresión "canibalismo genético" de un artículo de J. Attalí aparecido en la prensa diaria ${ }^{33}$, de donde también están tomadas las preguntas que he formulado, y otras equivalentes. De modo que, lejos del fragor de la acción, a estudiantes y lectores de diarios se les plantean preguntas como esas, mientras el pensamiento humanístico todavía no está seguro de si, tras la muerte de Dios, ha muerto también el hombre, o de si, tras la muerte de éste, a manos del estructuralismo de los años sesenta, hemos de recuperar una cierta hermeneútica del sujeto que Foucault cultivaba en sus cursos de los años ochenta. Parece que podemos pensar con Hegel que la filosofía siempre llega tarde para la solución de los problemas, puesto que, como el búho de Minerva, eleva su vuelo al anochecer. O podemos seguir a Heidegger por la senda de un pensar post-filosófico, que tal vez nos permita estar preparados para oir un sentido post-tecnológico del ser. Lo que parece claro es que lo único que se repite en la historia de la humanidad es que en el principio fue la acción o, en todo caso, que la acción viene antes que la palabra iluminadora. $\mathrm{O}$

${ }^{33}$ F. Fernández Buey, Ética y filosofía política, Barcelona, edicións Bellaterra, 2000, p. 281 
que, como nos señala Hans Jonas, las éticas habidas hasta ahora han dejado de ser suficientes para guiar nuestra acción en los dilemas actuales. Pero no es indiferente a la hora de resolver los problemas el modo de plantearlos, porque éste señala vías para búsqueda, que pueden resultar fructíferas o autenticos puntos muertos, sin que tengamos criterios previos para saberlo. Aceptar la novedad de la situación implica también asumir nuestra posición experiencial abierta y sin antecedentes, sabiendo también de la posibilidad de cometer errores individualmente irreparables. Aceptar la novedad de la situación implica, por tanto, aceptar los propios límites y, a la vez, la responsabilidad propia. Analicemos esta idea, comenzando por el significado de la palabra, una de las más usadas en la aludida conferencia de Sartre, y justamente la que ha sido elevada al rango de "principio" en la conocida obra de Hans Jonas. El diccionario de la academia nos ofrece dos caracterizaciones, sedimentadas en la palabra, sobre las que conviene reflexionar. La primera dice: "Deuda, obligación de reparar y satisfacer, por sí o por otro, a consecuencia de delito, de una culpa o de otra causa legal". En ella conviene señalar el cruce de motivos religiosos y jurídicos que lastran la noción; en primer lugar, la idea de "deuda", como vínculo de sujeto a sujeto, el primero deudor y el segundo acreedor. La de un responsable como alguien que debe algo tiene una clara raíz en la idea del hombre como ente limitado en su ser, que debe su vida a un creador. $Y$ desde éste, como se encargó de mostrar Nietzsche, se establece la responsabilidad como "equivalencia entre perjuicio y dolor", porque tiene su genealogía en "la relación contractual entre acreedor y deudor, que es tan antigua como los 'sujetos de derechos' y que, por su parte, remite a las formas básicas de compra, venta, cambio, comercio y tráfico" ${ }^{\prime 3}$. El marco jurídico y su trasposición teológica son proyecciones de una concepción del hombre que, para hacerlo calculable y controlable, limita y sacraliza sus vínculos

${ }^{34}$ F.Nietzsche, Genealogía de la moral, Madrid, Alianza, 1972, trad. cast. A. Sánchez Pascual, p.72.

Educ. e Filos., Uberlândia, v. 21, n. 42, p. 229-250, jul./dez. 2007. 
a las formas básicas de la compra y la venta. Una tal concepción del vínculo interhumano no puede ir más allá de la racionalidad instrumental de los subsistemas económico y jurídico, por más que los consagre teológicamente, para construir un tipo humano que responda a las preguntas que, como hemos visto, el desarrollo tecnológico plantea al hombre actual. Solo hay responsabilidades si hay deuda, a causa de delito, y ¿cuál es el delito cometido por querer estar sano y prolongar la vida, o mejorar genéticamente la salud de nuestros hijos, o querer conservar la comida por el frío, o circular más rápidamente? Por no decir nada de la idea de satisfacer y reparar ante alguien que, o bien no existe todavía - como es el caso de las generaciones futuras cuyos derechos a un ambiente saludable invocamos - , o bien será justamente "otro", otro efectuado por nuestra propia intervención genética. La responsabilidad ya no puede pensarse como deuda.

No sólo las éticas del pasado contienen una idea insuficiente del hombre para actuar en medio de las posibilidades tecnológicas presentes; contienen la huella de un origen social en el que aquellas posibilidades estaban reservadas a Dios, la naturaleza o el destino, y los valores creados en ese marco de posibilidades amenazan con remitirnos en direcciones equivocadas. Como señala Jonas al comienzo de El principio responsabilidad ni la condición humana puede ser considerada como fija en lo fundamental, ni sus valores pueden determinarse con claridad - contra lo que parecen pensar quienes hoy hablan de "educación en valores", la nueva ideología conservadora - ni el alcance de la acción humana está delimitado, por tanto, tampoco lo está el alcance de la responsabilidad.

Más aceptable resulta, a primera vista, por estar menos cargada de supuestos del pasado, una segunda caracterización de la responsabilidad, que encontramos en el mismo diccionario: "capacidad existente en todo sujeto activo de derecho para reconocer y aceptar las consecuencias de un hecho realizado libremente". Pero reparese en que no hay responsabilidad sin "sujeto activo de derecho", ni sin capacidad para "reconocer (...) las consecuencias", que deben ser, por tanto, conocidas. El camino descendente de Heidegger hacia un acontecer originario de verdad 
en un ser-ahí que no tenga la estructura del sujeto ha de complementarse con un camino ascendente que nos lleva a un nuevo tipo de sujeto, capaz de valorar las alternativas que hay en juego en las posibilidades que nos abre la tecnología; un sujeto que necesita la ciencia para prever, en lo posible, las consecuencias de las acciones que hoy ya puede realizar. Ese sujeto no puede prescindir del saber científico; necesita incluso incrementarlo en lo posible, pero no puede utilizarlo como guía, a diferencia del sujeto moderno, porque no puede dar por supuesta su propia identidad, que se basa en una auto-comprensión en mutación; ni puede contar con los valores heredados, ni extrae valores de la previsión científica. Necesita, por tanto, crearlos. Y necesita crearlos en una interacción social en la que no puede dar por supuesta ni la solidez ni la validez del vinculo social, tal como existe en la sociedad del presente. Un nuevo impulso a las ciencias sociales y a los saberes humanísticos, en cuyo seno siempre emergieron las perspectivas axiológicas, viene exigido por la transformación tecnológica de nuestras posibilidades de vida. 